\title{
Obesity Is in the Eye of the Beholder: BMI and Socioeconomic Outcomes across Cohorts
}

\author{
Vida Maralani, Douglas McKee \\ Cornell University
}

Abstract: The biological and social costs of body mass cannot be conceptualized in the same way. Using semiparametric methods, we show that the association between body mass index (BMI) and socioeconomic outcomes such as wages, being married, and family income is distinctly shaped by gender, race, and cohort rather than being above a specific threshold of BMI. For white men, the correlation between $\mathrm{BMI}$ and outcomes is positive across the "normal" range of BMI and turns negative near the cusp of the overweight range, a pattern that persists across cohorts. For white women, thinner is nearly always better, a pattern that also persists across cohorts. For black men in the 1979 cohort, the association between BMl and wages is positive across the normal and overweight ranges for wages and family income and inverted $\mathrm{U}$-shaped for marriage. For black women in the 1979 cohort, thinner is better for wages and marriage. By the 1997 cohort, however, the negative association between body mass and outcomes dissipates for black Americans but not for white Americans. In the social world, "too fat" is a subjective, contingent, and fluid judgment that differs depending on who is being judged, who does the judging, and the social domain.

Keywords: obesity; BMl; gender; race; wages; marriage

Citation: Maralani, Vida, and Douglas McKee. 2017. "Obesity Is in the Eye of the Beholder: BMI and Socioeconomic Outcomes across Cohorts." Sociological Science 4: 288-317.

Received: January 30, 2017

Accepted: February 27, 2017

Published: April 19, 2017

Editor(s): Jesper Sørensen, Stephen Morgan

DOI: $10.15195 / \mathrm{v} 4 . \mathrm{a} 13$

Copyright: (C) 2017 The Author(s). This open-access article has been published under a Creative Commons Attribution License, which allows unrestricted use, distribution and reproduction, in any form, as long as the original author and source have been credited. (0)(1)
UMEROUS studies link obesity to poorer socioeconomic outcomes, including lower wages, family income, education, marriage rates, and spousal earnings (Averett and Korenman 1996; Cawley 2004; Conley and Glauber 2007; Glass, Haas, and Reither 2010). But does the medical definition of "obese" apply to the social world? Obesity is a condition defined as having excessive body fat. Because body fat is difficult to measure directly, obesity is usually approximated by body weight adjusted for height using standard cutoffs along the body mass index (BMI) (Ogden et al. 2007). The continuous BMI scale is divided into four major intervals (underweight, normal, overweight, obese) with subclassifications of mild, moderate, and severe within these groupings. ${ }^{1}$ Although more accurate measures of body fat exist (e.g., waist-to-hip ratio, waist circumference, body volume index), these are far less commonly used in the social science research literature.

BMI is a flawed measure of actual body fat because it is not sensitive to differences in mass that are due to fat versus muscle or bone, and it misclassifies more African Americans as having excessive fat than white Americans (Burkhauser and Cawley 2008). However, it is a simple and standard measure that allows medical and public health studies to examine the biological links between this measure of corpulence and health-related outcomes. The BMI cutoff of 30 is used internationally as a standard medical definition of adult obesity. Once we move from biological to social outcomes, however, the definition of obesity becomes far more subjective. What counts as being excessively fat in the social world? 
A sizable literature demonstrates that the body is socially constructed and that our perceptions of fat bodies are tied to gendered and racialized norms of physical desirability and moral success (Lorber and Martin 2000; Saguy 2014). Body norms have also changed over time, as reflected by the tendency of the female body ideal to grow thinner and the male body ideal to grow more muscular in the twentieth century United States (Synnott 1992; Wiseman et al. 1992; Pope et al. 1999). Thus, although excessive body fat may be an objective condition when considering biological outcomes, in the social world, being "excessively fat" is a subjective condition. Before measuring the association between being excessively fat and a given socioeconomic outcome, we first have to ask the following: what counts as "too fat," for which social group, and with respect to what outcome?

In this study, we argue that in the social world, the definition of obesity or of being "too fat" is a thing itself to be studied. We use semiparametric methods to examine the association between BMI and outcomes across the distribution of BMI for different groups and over time. Our approach allows the association to differ within the standard categories of BMI; the association to be flat, positive, or negative in different parts of the distribution of BMI; and for each social group to have a different pattern of association across outcomes and cohorts. By studying a range of outcomes across groups and cohorts and using a flexible statistical approach, our results show the range of what might be interpreted as "too fat" in the social world.

Several studies of the relationship between body mass and wages show that this relationship differs distinctively by gender and race, suggesting that the social determination of norms surrounding what counts as "too fat" with respect to wages depends on social context. For example, for white men, the relationship between wages and BMI is inverted U-shaped, but for white women, it is largely a negative linear association across the distribution of body mass (Maranto and Stenoien 2000; Cawley 2004; Gregory and Ruhm 2011). Extending the results of these studies, we examine the association between body mass and socioeconomic outcomes using semiparametric methods across the distribution of BMI for several outcomes and across two birth cohorts. Our study asks: is the threshold for being "too fat," with respect to socioeconomic outcomes, a static or fluid concept? We first replicate the findings in the existing literature for three outcomes by race and gender using semiparametric methods and a nationally representative cohort sample. We then examine whether these associations have changed across birth cohorts as average BMIs have increased across the population. This is an important extension because it sheds light on the variability in the association between body size and socioeconomic outcomes over time. Finally, we replicate our cohort results with a different data set that includes both measured and self-reported height and weight to assess the robustness of our findings.

\section{Background}

We review the existing results for adults for the three outcomes we use in our analyses: wages, marriage, and family income. We then turn to the literature on body size norms, biases, and stigmas-which are important potential mechanisms linking BMI and socioeconomic outcomes-in order to motivate our approach. 


\section{Wages}

Some studies found an obesity wage penalty for both men and women (Averett and Korenman 1996; Maranto and Stenoien 2000; Baum and Ford 2004) whereas others found penalties for women but not for men or found that the penalty is in wage growth for men rather than wage levels (Register and Williams 1990; Loh 1993; Conley and Glauber 2007). Using an instrumental variables approach, Cawley (2004) found that obesity has a significant wage penalty only for white women. At the other end of the weight spectrum, underweight men face a smaller but still significant wage penalty (Lundborg, Nystedt, and Rooth 2014). The obesity wage penalty is not explained by health limitations but is instead related to occupational differences, which account for more than 20 percent of the effect of obesity on wages for both black and white women (Averett and Korenman 1996). Similarly, the negative relationship between BMI and wages is larger in occupations requiring interpersonal skills (Han, Norton, and Stearns 2009).

Using the standard BMI categories, however, misses a key aspect of the relationship between BMI and wages. Maranto and Stenoien (2000) found that the association between wages and BMI differs both by gender and race and is linear for women but quadratic for men. Using a semiparametric approach and a different data set, Gregory and Ruhm (2011) found similar results. Our study extends these approaches by considering two additional outcomes (the probability of being married and family income) and using change-point models to estimate where in the distribution of BMI the correlation between BMI and an outcome changes in a systematic way. We also examine whether the relationship between BMI and socioeconomic outcomes has changed across cohorts.

\section{Marriage}

Women who are obese are less likely to be married later in adulthood whereas the patterns are inconsistent for men (Gortmaker et al. 1993; Averett and Korenman 1996; Conley and Glauber 2007). Not only do obese women have lower probabilities of being married, but if they are married, their spouses earn less than the spouses of thinner women and are less physically attractive (Averett and Korenman 1996; Carmalt et al. 2008; Oreffice and Quintana-Domeque 2010).

\section{Family Income}

For family income, the most consistent finding is that obesity is associated with lower family income for white women but not for men (Averett and Korenman 1996; Chang and Lauderdale 2005; Conley and Glauber 2007). For white women, the lower probability of marriage and lower spousal earnings account for much of the difference observed in family income between obese and thinner women (Averett and Korenman 1999). 


\section{Bodies, Biases, and Stigmas}

One of the key differences between biological and social conceptualizations of "too fat" is that, in the social world, the determination of "too fat" depends on body norms, biases, and stigmas about having excessive fat. Individuals who are corpulent may face the double penalty of failing to meet beauty norms that reward thinness and of evoking negative stereotypes that cast people with excessive fat as lazy, less intelligent, or lacking self-control (Puhl and Heuer 2009). However, these norms, biases, and stigmas can vary considerably depending on who is being judged, who is doing the judging, and the context.

The literature consistently shows that obese individuals are stigmatized, albeit with differences by race and gender. Obese black Americans experience lower stigma than obese white Americans, regardless of gender, whereas obese women are more stigmatized than obese men (Hebl and Heatherton 1998; Puhl and Brownell 2001; Hebl and Turchin 2005). Men also judge obese individuals more harshly than women do (Fletcher 2014). But the existing results about differences in groupspecific norms and biases are inconsistent despite prevailing beliefs that African Americans and Latinos are more accepting of people with larger bodies than whites are (Altabe 1998; Cachelin et al. 2002; Glasser, Robnett, and Feliciano 2009). Individuals also have different body size ideals for their own race and/or ethnic group versus across races (Hebl and Turchin 2005; Fletcher 2014). Few studies examine whether there is a particular threshold that evokes biases or if this threshold has changed over time.

By looking across three outcomes and two cohorts, we evaluate the potential evidence for the stability or fluidity of being "too fat" or "thin enough" across a range of contexts. If "too fat" is a stable construct, we expect to find similar patterns for each group across the three outcomes. Alternatively, labor and marriage markets may differ in cultural norms about corpulence because couples match on numerous characteristics including education, income, and BMI, which makes marriage markets more homogenous than labor markets (Kalmijn 1998; Speakman et al. 2007). Marriage is also distinct for having extremely high levels of racial homogamy (Kalmijn 1998), which suggests that in this domain, cultural norms about weight operate across gender but largely within race. In contrast, in the labor market, differences in body norms are likely to operate across both gender and race. Family income is an outcome that sits at the intersection of the labor and marriage markets, and it is likely to encompass a combination of these mechanisms.

Our analyses also examine how these associations change over time. It is possible that increases in average BMI across cohorts, especially among those groups with lower socioeconomic status, may have strengthened status distinctions by body weight and have made body size more central in wage and marriage markets over time. Alternatively, as BMI has increased across all groups, the stigma of excessive weight might have declined in certain domains, suggesting weaker socioeconomic penalties than in the past. Numerous studies on gender and bodies show that norms about thinness apply more strongly to women than to men (Sobal and Stunkard 1989; Bordo 1993) and thus may change more slowly for women than men. Extending these ideas to the intersection of gender and race suggests a potentially more nuanced interaction over time, with persisting or even increasing 
norms of thinness for white women but weaker norms or potentially faster change for black women.

\section{Analytical Approach}

\section{Data}

The analyses use two nationally representative birth cohorts of Americans from the National Longitudinal Surveys of Youth in 1979 (NLSY-79) and 1997 (NLSY-97). The NLSY surveys include detailed longitudinal information on employment, wages, marriage, fertility, education, and family income and are similar in design across cohorts. The 1979 sample includes respondents who were ages 14 to 22 when first surveyed in 1979. The 1997 sample includes respondents who were 12 to 17 when first interviewed in 1997. In order to make the cohorts comparable, we excluded the military and poor white oversamples from the 1979 cohort but retained the oversamples of black youth. Because the Hispanic samples are too small to analyze separately, we omitted this group and restricted our analyses to black and white respondents. We conducted all our analyses separately by race, sex, and birth cohort. Our analytic sample includes 5,890 respondents from the 1979 cohort and 6,082 respondents from the 1997 cohort.

Many studies on the relationship between BMI and socioeconomic outcomes use the design of Averett and Korenman (1996), who measure BMI in early adulthood and use this early measure to predict outcomes seven years later. This lag measure helps ensure the correct time ordering of BMI to outcomes. Because our study is in part a replication of the existing literature, we also use this approach. This design has the advantage of reducing confounding and reverse causality at the cost of ignoring potential changes in BMI during the seven-year gap that might inform these outcomes. ${ }^{2}$ We departed from Averett and Korenman's approach, however, by restricting our analyses to respondents ages 19 and older so we do not confound adolescent and adult BMI measures (Centers for Disease Control and Prevention 2000; Gordon-Larsen 2004). We describe our sample construction in more detail in the online supplement.

The height and weight information in these data sets are self-reported, as they are in the vast majority of existing studies relating BMI to socioeconomic outcomes. We checked the sensitivity of our results to using self-reported weight and height by replicating a subset of our results using a different data set that has both measured and self-reported weight for a cohort that overlaps with the NLSY-97. We describe these data and analyses below in the section on sensitivity checks.

We constructed the baseline measures of BMI using an average across two waves. For the 1979 cohort, we used an average of BMI measured in 1981 and 1982, and for the 1997 cohort, we averaged BMIs computed from the 2003 and 2004 waves. When a respondent had only one measure of BMI available across the two waves, we used that value as the baseline measure. For simplicity, we call these average baseline measures "BMI in 1981" and "BMI in 2003." We measured outcomes seven years later, in 1988 and 2010, respectively, when respondents were ages 26 to 31 . These 
two cohorts are separated by 22 years and straddle the increase in the distribution of BMI documented in the United States.

We studied the relationship between body mass and socioeconomic outcomes across two domains: work and marriage. The outcomes include wages, the probability of being married, and total family income. Wages are measured as log hourly wages reported for the respondent's current job at the time of the interview in 1988 or 2010. We converted the 2010 values to 1988 dollars so that values across cohorts can be compared in real terms. We analyzed the probability of being currently married from the respondents' marital status in 1988 or 2010 for those who were never married in the baseline year when BMI was measured (1981 or 2003). Total family income is an NLSY-constructed variable that combines the incomes of household members related to the respondent by blood or marriage. ${ }^{3}$ We recoded respondents with a family income of zero to a value of $\$ 5$ and used log family income as our dependent variable (rescaled to 1988 dollars). Our substantive results do not change if we omit those with zero family income from the sample ( $N=47$ in NLSY-79 and $N=115$ in NLSY-97 cohorts), and BMI is not associated with having zero family income.

Wage and marriage outcomes depend on other characteristics that are correlated with BMI such as education, occupational characteristics, and region of residence. Omitting these variables from the analyses may overstate the association between $\mathrm{BMI}$ and the outcomes. On the other hand, if these characteristics are themselves caused by BMI, then including them as controls would bias our results. We have conducted all analyses with and without controls for education, occupational characteristics, and region, and the results are substantively the same. Below, we report the results with the background factors included.

The results reported below control for education, the percentile score on a test of cognitive skills (Armed Forces Qualification Test [AFQT] in NLSY-79 and the Armed Services Vocational Aptitude Battery [ASVAB] in NLSY-97), age in singleyear categories, urban or rural residence, region of residence, and metropolitan statistical areas (SMSA). ${ }^{4}$ The models with wages as dependent variables also control for years of work experience and occupational sector using a collapsed six-category census occupation coding for 1980 and 2000. These categories are (1) managerial, professional; (2) technical, sales, administrative; (3) service; (4) farming, forestry, fishing; (5) skilled crafts, construction; and (6) operators, laborers. The models for family income include an additional control for whether the respondent was living with at least one parent. All covariates are measured in the same year as the outcomes (1988 or 2010) except for standardized tests of cognitive skills, which were collected in 1980 and 1997, respectively.

In each cohort, we analyzed outcomes separately for each of the four social groups (white men, black men, white women, and black women). Table 1 shows sample statistics for the variables used in the analyses, stratified by social group, for those with valid information on wages. The sample sizes for each outcome differ depending on the valid responses available for each outcome and are presented in the Results section. 


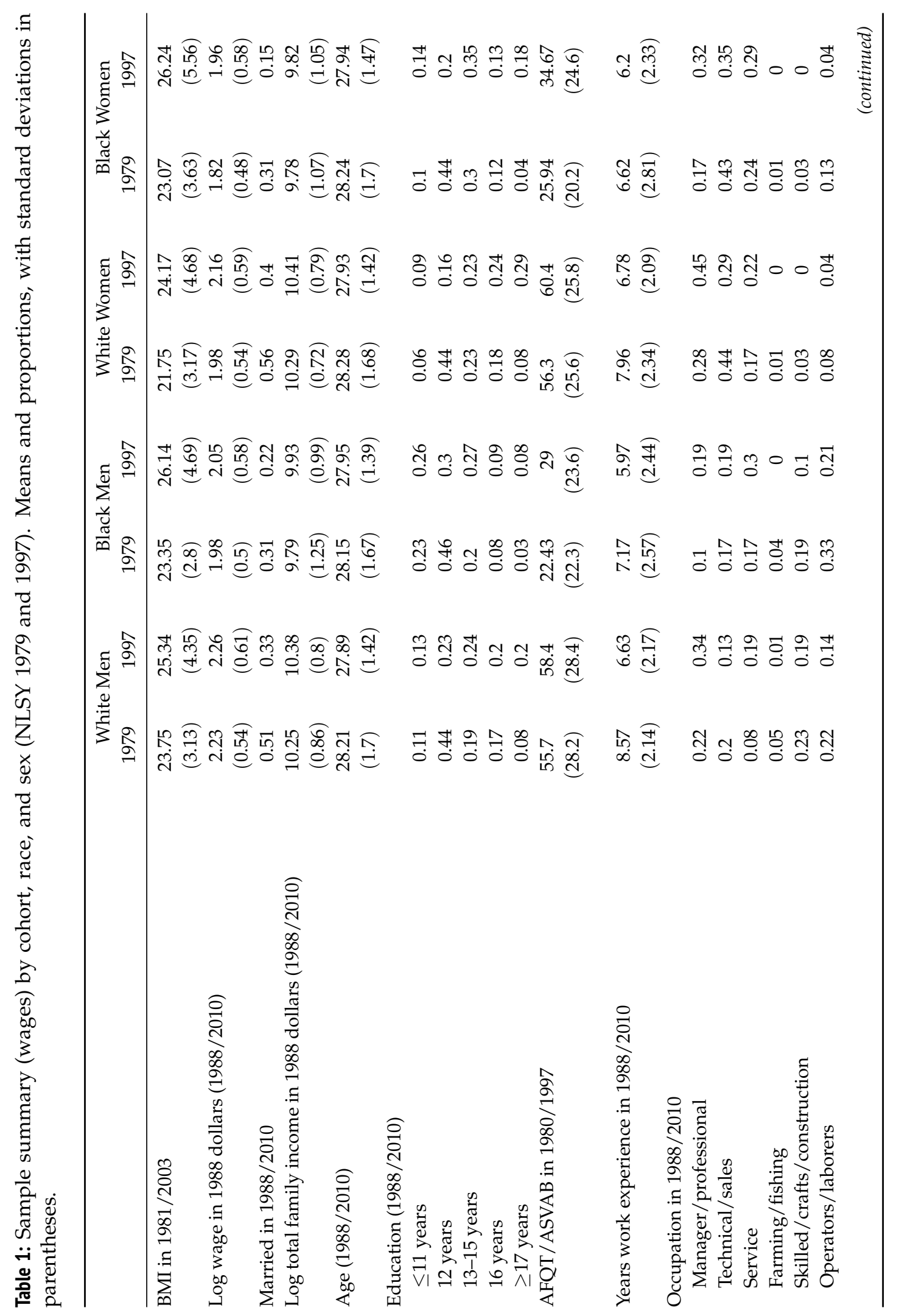




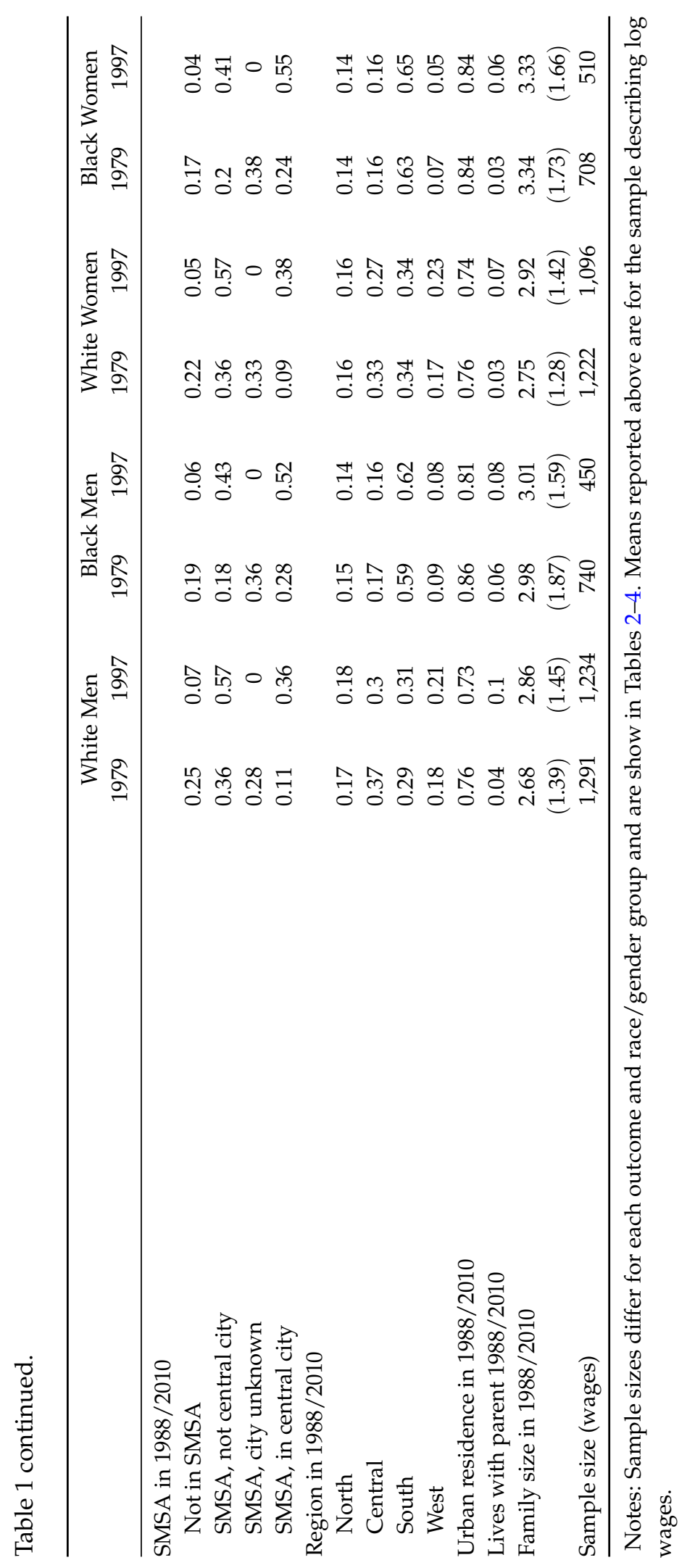




\section{Methods}

We used two statistical approaches in our analyses. The first was semiparametric locally weighted least-squares regression, controlling for covariates, which specifies each outcome as a composite of a nonparametric function of BMI and a parametric function of a set of other covariates (Yatchew 1998). We describe this method in detail in the online supplement. We bootstrapped these regressions to trace out the 95 percent confidence interval around our estimates of the nonparametric functions. These regressions allow us to describe the underlying association between BMI and each outcome for each social group and cohort-controlling for the personal characteristics described in the data section above-in an extremely flexible way.

Locally weighted regression is a flexible, descriptive tool, but it does not say anything precise about the association between BMI and a given outcome. In order to quantify these relationships, our second statistical approach was to use change-point models to estimate differences in the association between BMI and each outcome within different ranges of BMI (Zacks 1982; Bhattacharya 1994; Hall et al. 2000). This method is an extension of a standard linear spline model in which the locations of the "knots" are treated as parameters that are empirically estimated rather than specified as given. Again, we bootstrapped to get 95 percent confidence intervals for the change points and slopes reported.

The estimated change points mark where in the distribution of BMI the association between BMI and a given outcome changes direction or becomes steeper or flatter. For example, if the association between BMI and log wages is positive from a BMI of 17 to 27 (a pattern that is consistent with a more muscular body norm for men) but then turns negative between 27 and 35 (a pattern consistent with an increasing disadvantage of having higher BMI), and if this change point (27) maximizes the log likelihood of the model given the data, then this is the value of BMI selected as the change point in the estimation. In a standard spline model, the location of this point must be specified a priori.

The example above describes a one-change-point pattern, but the approach can be used to estimate more complex patterns as well. We estimate models that allow for up to two change points (three different slopes) and then use likelihood ratio (LR) tests to determine whether the two-change-point model fits the data better than the single-change-point model. If, for example, the association between BMI and log wages is instead about the same from a BMI of 17 to 22, then increases between a BMI of 22 and 27, then turns negative between a BMI of 27 and 35, then a two-change-point model can capture this pattern (change points at BMIs of 22 and 27). A single-change-point model, in contrast, could only capture two different patterns of association rather than three. We first fit the more complicated model, then fit the simpler model and used LR tests to decide which model best captured the observed patterns.

The association between BMI and a given outcome could, of course, be simplerit could be relatively constant across the range of BMI. This pattern is captured by a simple line, and we also used LR tests to assess whether the single-change-point model fit better than a line with a single slope.$^{5}$ This is an important possibility to test because a simple downward-sloping line across the distribution of BMI can look like an obesity penalty-the mean outcome will be lower at BMIs greater than 
30 than at BMIs less than 30-but the underlying patterns are in fact about being thin rather than being fat because the outcome will have the highest average value at the lowest values of BMI.

Our approach and findings are descriptive. Our results describe correlations rather than causal relationships, and we interpret them only in this way. These descriptive results, however, are an essential part of understanding the relationship between body size and socioeconomic outcomes. Before we can estimate the causal effect of being "too fat" on socioeconomic outcomes, we must first examine whether taking a categorical view of bodies as being "too fat" is a reasonable assumption for studying outcomes in the social world. As we show in our results below, "too fat" turns out to be a contingent and fluid concept.

\section{Results}

The figures that follow show the semiparametric regression results for the association between BMI in early adulthood and three socioeconomic outcomes (wages, the probability of being married, and log family income) measured seven years later and adjusting for covariates. The figures include vertical, dotted lines showing the standard BMI cutoffs for being "underweight" (<18.5), "normal" weight (18.5-24.9), "overweight" (25-29.9), and "obese" ( $\geq 30)$. The tables that follow show the results for the accompanying set of change-point models for both cohorts. Although our discussion of the results integrates the information shown in the figures and tables, the semiparametric regressions and the change-point models are two unrelated statistical approaches. The semiparametric regressions estimate the correlation between BMI and a given outcome across the distribution of BMI. The change-point models fit two- or three-piece linear spline models in which the knots (change points) are estimated empirically. We first describe the results for the 1979 cohort so that we can compare patterns across outcomes within the cohort, and then we turn to changes across cohorts by describing the results for the 1997 cohort.

\section{Cohort Wages}

Figure 1 shows the semiparametric regression results for the correlation between BMI in 1981 and log hourly wages in 1988. For white men, wages increase as BMI increases across the underweight and normal ranges, with the curve peaking at the cusp of the overweight range. The change-point model results summarized in Table 2, column 1 show that wages peak for white men at a BMI of 25.1 with a 95 percent confidence interval from 20.8 to 25.8. Each one-unit increase in BMI from 17 to 25.1 is associated with an increase in log hourly wages of 0.031 . In contrast, the wages of white men decrease across the entire overweight and obese range with a slope of -0.034 . The LR test result shows that we can reject the hypothesis that a simple line fits this pattern. White men's wages begin to decline not only before the standard cutoff for obesity but at the start of the overweight range. The confidence interval for the change point straddles the normal weight range. Moreover, wages increase as BMI increases across the normal BMI range. This suggests that white 
Table 2: Results from change-point models for log wages by cohort.

(1)

(2)

1979 Cohort

1997 Cohort

\begin{tabular}{|c|c|c|}
\hline \multicolumn{3}{|l|}{ White men } \\
\hline Change point & 25.1 & 24.4 \\
\hline $95 \%$ confidence interval & {$[20.8,25.8]$} & {$[20.8,29.5]$} \\
\hline Slope 1 & $\begin{array}{r}0.031 * \\
(0.008)\end{array}$ & $\begin{array}{r}0.047 * \\
(0.011)\end{array}$ \\
\hline Slope 2 & $\begin{array}{r}-0.034 * \\
(0.009)\end{array}$ & $\begin{array}{r}-0.014 * \\
(0.006)\end{array}$ \\
\hline Change point fits ${ }^{\mathrm{a}}$ & $p<0.01$ & $p<0.01$ \\
\hline Slope of simple line & -- & -- \\
\hline$N$ & 1,291 & 1,234 \\
\hline \multicolumn{3}{|l|}{ Black men } \\
\hline Change point & 27.6 & 32.5 \\
\hline $95 \%$ confidence interval & {$[18.1,34.6]$} & {$[18.5,39.9]$} \\
\hline Slope 1 & $\begin{array}{r}0.021 * \\
(0.008)\end{array}$ & $\begin{array}{c}0.008 \\
(0.008)\end{array}$ \\
\hline Slope 2 & $\begin{array}{r}-0.028 \\
(0.02)\end{array}$ & $\begin{array}{r}-0.035 \\
(0.023)\end{array}$ \\
\hline Change point fits ${ }^{\mathrm{a}}$ & $p=0.12$ & $p=0.28$ \\
\hline Slope of simple line & $\begin{array}{r}0.011+ \\
(0.006)\end{array}$ & $\begin{array}{c}-0.001 \\
(0.006)\end{array}$ \\
\hline$N$ & 740 & 450 \\
\hline \multicolumn{3}{|l|}{ White women } \\
\hline Change point & 31.5 & 23.1 \\
\hline $95 \%$ confidence interval & {$[18.1,33.4]$} & {$[18.1,33.1]$} \\
\hline Slope 1 & $\begin{array}{c}0.003 \\
(0.004)\end{array}$ & $\begin{array}{r}-0.025 * \\
(0.012)\end{array}$ \\
\hline Slope 2 & $\begin{array}{r}-0.125 * \\
(0.042)\end{array}$ & $\begin{array}{r}-0.009+ \\
(0.005)\end{array}$ \\
\hline Change point fits ${ }^{\mathrm{a}}$ & $p=0.02$ & $p=0.52$ \\
\hline Slope of simple line & -- & $\begin{array}{r}-0.012 * \\
(0.003)\end{array}$ \\
\hline$N$ & 1,222 & 1,096 \\
\hline & & (continued) \\
\hline
\end{tabular}

men are disadvantaged both when they are quite thin and when they are corpulent. For this group, log wages are highest at the upper end of the normal weight range.

For black men, the semiparametric results suggest that the relationship between $\mathrm{BMI}$ and log hourly wages is also inverted U-shaped, although the rise across the normal range is not as steep and the peak not as distinct as it is for white men. The curve is upward sloping across the normal and overweight ranges. The change- 
Table 2 continued.

(1)

(2)

1979 Cohort

1997 Cohort

\begin{tabular}{lrc}
\hline Black women & & \\
Change point & 20.7 & 22.2 \\
$95 \%$ confidence interval & {$[18.0,31.6]$} & {$[18.0,38.3]$} \\
Slope 1 & $0.055 *$ & 0.021 \\
& $(0.022)$ & $(0.024)$ \\
Slope 2 & $-0.011 *$ & $-0.010 \dagger$ \\
& $(0.005)$ & $(0.005)$ \\
Change point fits ${ }^{\mathrm{a}}$ & $p=0.03$ & $p=0.50$ \\
Slope of simple line & -- & -0.006 \\
& & $(0.004)$ \\
$N$ & 708 & 510 \\
\hline
\end{tabular}

$* p<0.05,+p<0.10$. Standard errors of slope coefficients in parentheses.

a $p$ value for LR test that an endogenous change point with slopes on each side fits better than a single-slope line.

point model results suggest, however, that a simple upward-sloping line captures the pattern as well as the nonlinear model (the LR test of the null hypothesis that a line fits at least as well as the nonlinear model has a $p$ value of 0.12 ). When we fit this simple line, it has a slope of $0.011(p<0.08)$. Figure 1 shows that the support for this positive association between BMI and wages for black men comes from those with BMIs between 20 and 27-the semiparametric curve rises steadily across the normal and overweight ranges-rather than from BMIs greater than 30 .

The relationship between log hourly wages and BMI is much different for women than it is for men. For white women, Figure 1 shows a flat relationship across the normal and overweight ranges and then a decline that begins at a BMI of 31.5. The change-point model estimates a flat slope from a BMI of 17 to 31.5 and then a negative slope $(-0.125)$ from 31.5 to 35 (because the pattern is a flat line in the first interval, the lower confidence bound is necessarily wide in this case). The LR test results show that this two-slope specification fits the data better than a simple line. The results for white women in the 1979 cohort are consistent with the idea of an "obesity penalty." The association between BMI and wages appears flat until the top of the BMI distribution. Starting at a BMI of about 32, white women's wages show a linear decline with each additional unit increase in BMI.

For black women, the semiparametric regression results show a positive association between log wages and BMI up to a BMI of 21, then a negative correlation across the remainder of the distribution of BMI. The change-point model estimates a slope of 0.055 from a BMI of 17 to 20.7 and a downward slope of -0.011 from a BMI of 20.7 to 35, although the change point itself has a wide confidence interval from 18 to 31.6. This suggests that although we cannot estimate precisely where the curve turns from positive to negative, the interval where it turns covers little of the obese range. The semiparametric results show the curvature at very low levels of BMI, which supports this conclusion as well. The LR test rejects the hypothesis 

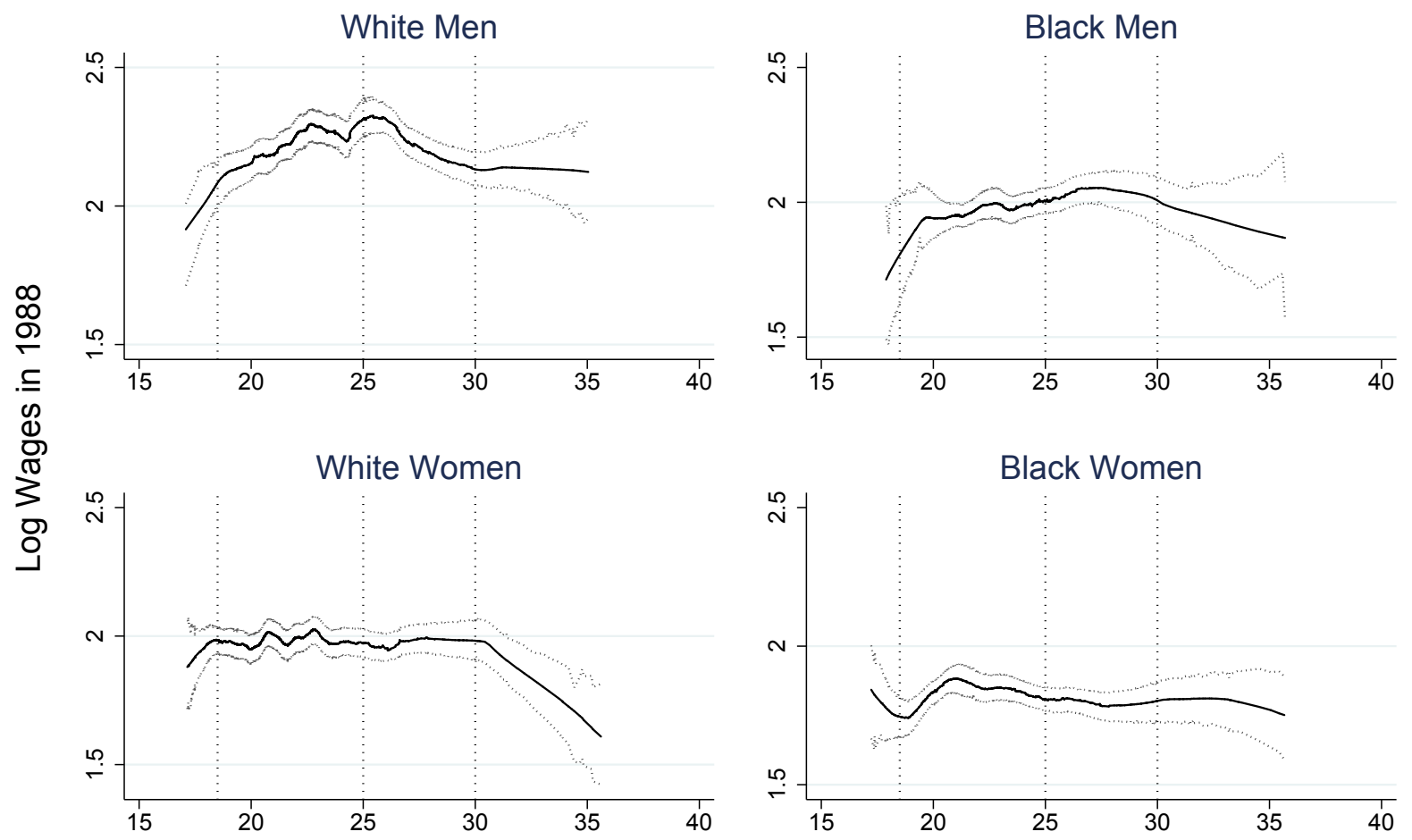

BMl in 1981

Figure 1: Results from semiparametric linear regression of log wages in 1988 on BMI in 1981, NLSY-1979.

Notes: Vertical, dotted lines show standard BMI cutoffs: <18.5, “Underweight”; 18.5-24.9, “Normal”; 25-29.9, “Overweight”; $\geq 30$, "Obese." Models control for education, age, AFQT, region of residence, work experience, and industry.

that a simple line fits the data. Although black women do not have the same sharp decline in wages in the obese range as was observed for white women, the negative association between BMI and log wages across the normal and overweight ranges is inconsistent with the idea that black women are not penalized for having larger bodies. The negative association between wages and BMI for this group begins at a range of body size that is quite thin by any standard.

\section{Cohort Marriage}

Figure 2 and Table 3, column 1 show the results for the probability of being married for the 1979 cohort. For white men, the probability of being married increases across the underweight and normal ranges and then decreases across the overweight and obese ranges. The change point results show that a one-unit increase in BMI is associated with an increase of 0.028 in the probability of being married up to a BMI of 23.3 and then a decrease of -0.018 from a BMI of 23.3 to 35 . Black men in this cohort display a similar pattern: the probability of being married increases up to a BMI of 26.7 and then decreases from a BMI of 26.7 to 35. For both white and black 

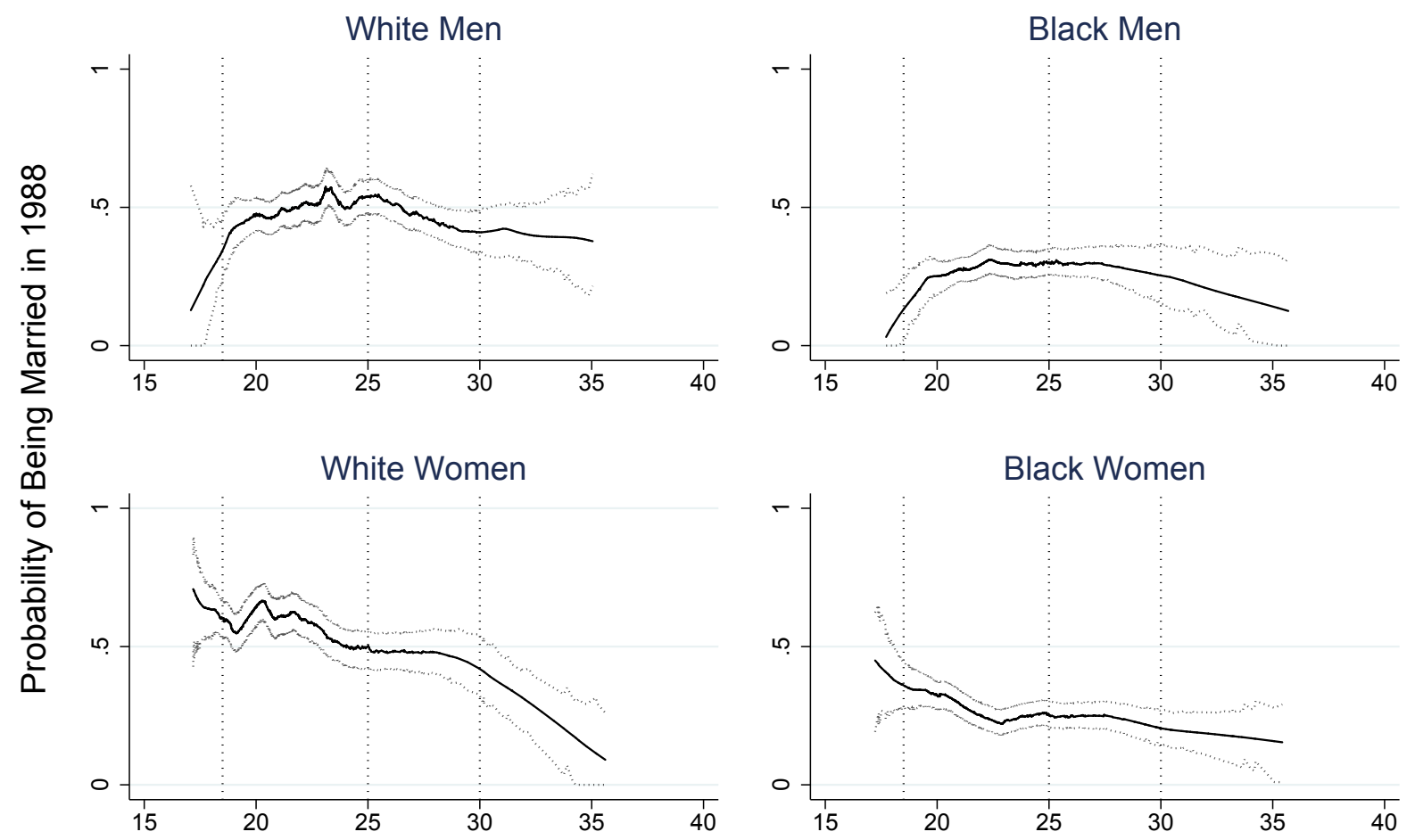

BMl in 1981

Figure 2: Results from semiparametric linear regression of the probability of being married in 1988 on BMI in 1981, NLSY-1979.

Notes: Vertical, dotted lines show standard BMI cutoffs: <18.5, “Underweight”; 18.5-24.9, “Normal”; 25-29.9, “Overweight"; $\geq 30$, "Obese." Models are linear probability models estimated only for those never married in 1981 and control for education, age, AFQT, and region of residence.

men, the change point itself (the point where the correlation turns from positive to negative) is estimated imprecisely, but the LR test results support a nonlinear pattern, and the semiparametric results show a curvilinear pattern for both groups of men with respect to the probability of being married centered in the middle of the distribution of BMI rather than at the low or high ends.

In contrast, for both white and black women in the 1979 cohort, the relationship between BMI and the probability of being married is adequately captured by a simple downward-sloping line. For white women, the slope of this line is -0.019 , whereas for black women, the slope is -0.011 . Regardless of race, women's probability of being married is highest at very low BMIs and declines steadily thereafter. These results show no evidence for an obesity penalty in marriage, nor do they support the idea that black men are more accepting of larger women than are white men. Instead, the evidence suggests that a body ideal of thinness prevailed in the domain of marriage for both white and black women for the 1979 cohort. 
Table 3: Results from change-point models for marriage by cohort.

(1)

(2)

1979 Cohort 1997 Cohort

White men

Change point

$95 \%$ confidence interval

Slope 1

Slope 2

Slope 3

Change point fits

Slope of simple line

N

Black men

Change point

95\% confidence interval

Slope 1

Slope 2

Change point fits ${ }^{\mathrm{a}}$

Slope of simple line

N

White women

Change point

95\% confidence interval

Slope 1

Slope 2

Change point fits ${ }^{\mathrm{a}}$

Slope of simple line

N
$23.3 \quad 23.8 ; 26.8$

$[18.8,33.9] \quad[18.0,35.3]$

[25.4, 38.8]

0.028* $\quad-0.006$

$(0.012) \quad(0.01)$

$-0.018 * \quad 0.050 *$

(0.007) (0.014)

$-0.015 *$

$(0.006)$

$p=0.02^{a} \quad p<0.05^{b}$

$--\quad--$

$1,105 \quad 1,359$
$[18.9,32.0] \quad[21.0,34.5]$

$0.017 * \quad 0.038 *$

$(0.008) \quad(0.014)$

$-0.028+\quad-0.007$

(0.016) (0.005)

$p=0.09 \quad p=0.03$

$0.004 \quad--$

(0.006)

762

636

28.2

32.7

$[18.0,34.8] \quad[18.0,39.9]$

$-0.012+\quad-0.003$

$(0.007) \quad(0.004)$

$-0.056 * \quad-0.026+$

$(0.022)$

$(0.015)$

$p=0.23 \quad p=0.38$

$-0.019 * \quad-0.006 *$

(0.005) (0.003)

931

1,127

(continued)

\section{Cohort Family Income}

As shown in Figure 3, for white men, BMI and family income have a positive association across the normal range, and this association turns negative in the 
Table 3 continued

(1)

1979 Cohort
(2)

1997 Cohort

\begin{tabular}{lcc}
\hline Black Women & & \\
Change Point & 22.2 & 18 \\
$95 \%$ confidence interval & {$[18.0,33.3]$} & {$[18.0,38.4]$} \\
Slope 1 & $-0.032 *$ & $-0.537 \dagger$ \\
& $(0.015)$ & $(0.306)$ \\
Slope 2 & -0.005 & -0.003 \\
& $(0.007)$ & $(0.003)$ \\
Change point fits ${ }^{\mathrm{a}}$ & $p=0.34$ & $p=0.21$ \\
Slope of simple line & $-0.011 *$ & -0.004 \\
& $(0.005)$ & $(0.003)$ \\
$N$ & 718 & 638 \\
\hline
\end{tabular}

Change Point

$[18.0,38.4]$

$-0.032 *$

$-0.537$

$-0.005$

Change point fits ${ }^{\mathrm{a}}$

$=0.21$

$-0.011 *$

$* p<0.05,+p<0.10$. Standard errors of slope coefficients in parentheses.

a $p$ value for LR test that an endogenous change point with slopes on each side fits better than a single-slope line.

${ }^{b} p$ value for LR test that endogenous two-change-point model with three slopes fits better than a single-slope line.

overweight and obese ranges. The change point results in Table 4, column 1 suggest that the association turns from positive to negative at a BMI of 27, with a slope of 0.04 up to a BMI of 27 and a slope of -0.09 from a BMI of 27 to 35 . For black men, the LR test does not reject the hypothesis that a simple upward-sloping line fits as well as the nonlinear model. The association between family income and BMI for black men is captured by a single positive slope of 0.055 . For white women, the association between BMI in 1981 and $\log$ family income seven years later is negative across nearly the entire range of BMI (18.7 to 35). For black women, there appears to be no meaningful association between family income and BMI.

To summarize the results for the 1979 cohort, the association between BMI and outcomes is distinctly shaped by gender in this cohort. For men, "too fat" seems to begin in the middle of the distribution of BMI, but outcomes are also worse for "too thin" men. The pattern for all three outcomes is inverted U-shaped for white men with the association turning from positive to negative well below the standard threshold for being "obese." For black men, the pattern is similarly inverted U-shaped for marriage but primarily upward sloping across the middle of the distribution of BMI for wages and family income. For white and black women, in contrast, the concept of "too fat" does not seem to apply because average outcomes are highest at very low values of BMI. Instead, the predominant pattern is "thinner is better." In most cases, we find a negative association between BMI and socioeconomic outcomes across much of the distribution of BMI. The exceptions to this pattern are wages for white women, which show a pattern consistent with an obesity penalty, and family income for black women, which has no significant association with BMI. Next, we examine whether the patterns we see in the 1979 cohort are still apparent 20 years later. 

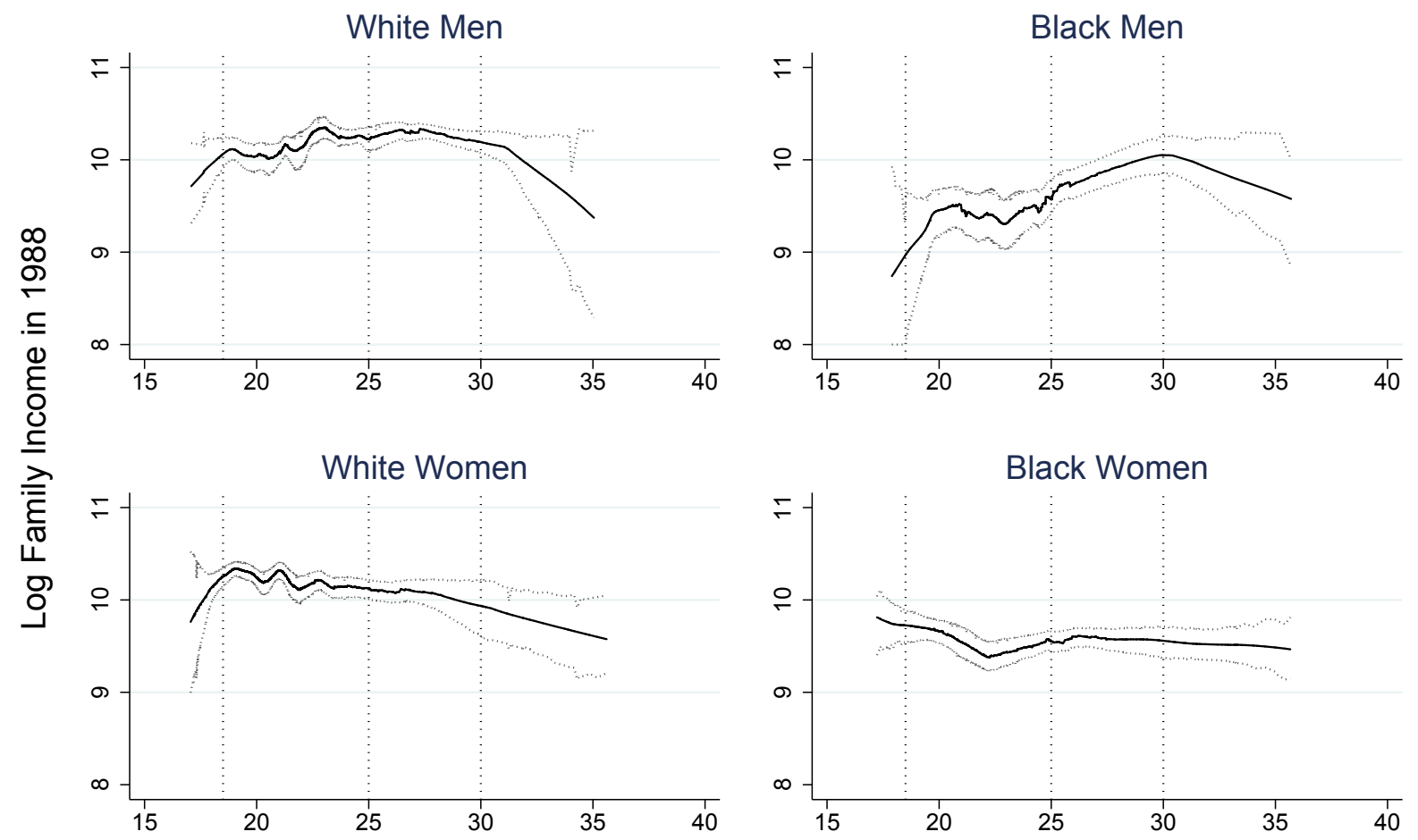

BMl in 1981

Figure 3: Results from semiparametric linear regression of log family income in 1988 on BMI in 1981, NLSY1979.

Notes: Vertical, dotted lines show standard BMI cutoffs: <18.5, “Underweight"; 18.5-24.9, "Normal”; 25-29.9, “Overweight"; $\geq 30$, "Obese." Models control for education, age, AFQT, region of residence, and whether the respondent lived with a parent in 1988.

\section{Cohort Wages}

Figure 4 and Table 2, column 2 describe the association between BMI in 2003 and log wages in 2010 (adjusted to 1988 dollars) for the 1997 cohort. For ease of comparison, the graphs also show the curve for the 1979 cohort with a dashed line. For white men, the association between BMI and wages is quite similar across cohorts. Again, the relationship is inverted U-shaped, with a change point at 24.4 and slopes of 0.047 and -0.014 on either side of this change point. For black men in the 1997 cohort, the association between BMI and wages is flatter in the normal range, and the change point results also capture this weaker association.

For white women in the 1997 cohort, the pattern changes substantially, and we now cannot reject the hypothesis that a simple downward-sloping line across the distribution of BMI fits as well as the nonlinear model. The "obesity penalty" observed in the 1979 cohort transforms to a pattern more consistent with body norms rewarding thinness. For black women, the semiparametric curve for the 1997 cohort is flatter in the normal range but otherwise has a similar shape across 
Table 4: Results from change-point models for log family income by cohort.

1979 Cohort

White men

Change point

$95 \%$ confidence interval

Slope 1

Slope 2

Change point fits ${ }^{\mathrm{a}}$

Slope of simple line

$N$

Black men

Change point

95\% confidence interval

Slope 1

Slope 2

Change point fits ${ }^{\mathrm{a}}$

Slope of simple line

N

White women

Change point

95\% confidence interval

Slope 1

Slope 2

Change point fits ${ }^{\mathrm{a}}$

Slope of simple line

N
(1)

(2)

1997 Cohort

27

19.9

$[22.6,33.4]$

$0.043 *$

$(0.014)$

$-0.090 *$

$(0.028)$

$p<0.01$

$--$

1,151

$[18.3,39.4]$

$0.250+$

(0.128)

0.001

(0.009)

$p=0.16$

0.007

(0.008)

1,311

33.9

19.5

[18.1, 33.9]

[18.6, 34.7]

$0.066 *$

0.649

(0.028)

(0.86)

$-0.985$

0.03

(0.808)

(0.022)

$p=0.42$

$p=0.77$

0.055*

(0.027)

602

0.033

(0.021)

533

18.7

25.9

[18.0, 33.0]

[18.1, 39.9]

$0.258 *$

$-0.017$

(0.107)

(0.014)

$-0.033 *$

0.003

$(0.009)$

(0.012)

$p=0.03$

$p=0.68$

$--$

$-0.006$

1,287

1,184

(continued)

cohorts. The change point results also reflect this flattening at the lower BMI range; we cannot reject that a simple flat line fits the pattern for black women.

The results suggest that perceptions of body size may have changed across cohorts differently by race and gender in ways that are consistent with a normalizing of corpulence for black men and women, a reinforcement of thin beauty ideals for 
Table 4 continued.

(1)

1979 Cohort
(2)

1997 Cohort

\begin{tabular}{lcc}
\hline Black women & & \\
Change point & 21.7 & 35 \\
95\% confidence interval & {$[18.7,32.5]$} & {$[19.7,39.5]$} \\
Slope 1 & $-0.090 *$ & $-0.036 *$ \\
& $(0.044)$ & $(0.015)$ \\
Slope 2 & -0.011 & 0.122 \\
& $(0.016)$ & $(0.079)$ \\
Change point fits ${ }^{\mathrm{a}}$ & $p=0.16$ & $p=0.18$ \\
Slope of simple line & -0.009 & -0.02 \\
& $(0.012)$ & $(0.012)$ \\
$N$ & 728 & 605 \\
\hline
\end{tabular}

$* p<0.05,+p<0.10$. Standard errors of slope coefficients in parentheses.

a $p$ value for LR test that endogenous change point with slopes on each side fits better than single slope line.

white women, and a status quo of a midrange body size that is neither too thin nor too large for white men. We discuss the implications of these changes across cohorts in the discussion section below.

\section{Cohort Marriage}

Figure 5 and Table 3, column 2 describe the correlation between BMI in 2003 and the probability of being married in 2010. For white men in the 1997 cohort, a twochange-point model fits the data. The association between BMI and the probability of marriage is flat from a BMI of 17 to about 24, positive between BMIs of about 24 and 27, and then negative across the rest of the overweight and obese ranges (BMIs of 26.8 to 40). The overall shape of the association between BMI and wages, however, remains inverted U-shaped for white men in both cohorts. The entire curve is lower for the 1997 cohort compared with the 1979 cohort, which reflects the broader demographic trends of the increasing age at marriage and the overall decline in the probability of marriage across cohorts. We discuss the implication of these broader demographic trends in more detail below.

For black men in the 1997 cohort, the probability of being married has a flatter relationship with BMI than it did in the previous cohort, especially at higher levels of body mass. The likelihood of being married rises across the normal range of BMI and then remains flat across the overweight and obese ranges. The change-point model estimates a rising slope of 0.038 from a BMI of 17 to about 24 and then no association between BMI and the probability of marriage across the remainder of the distribution of BMI. The negative association between the probability of being married and body mass for larger black men disappears across the two cohorts, whereas the positive association across the normal range persists across cohorts. 

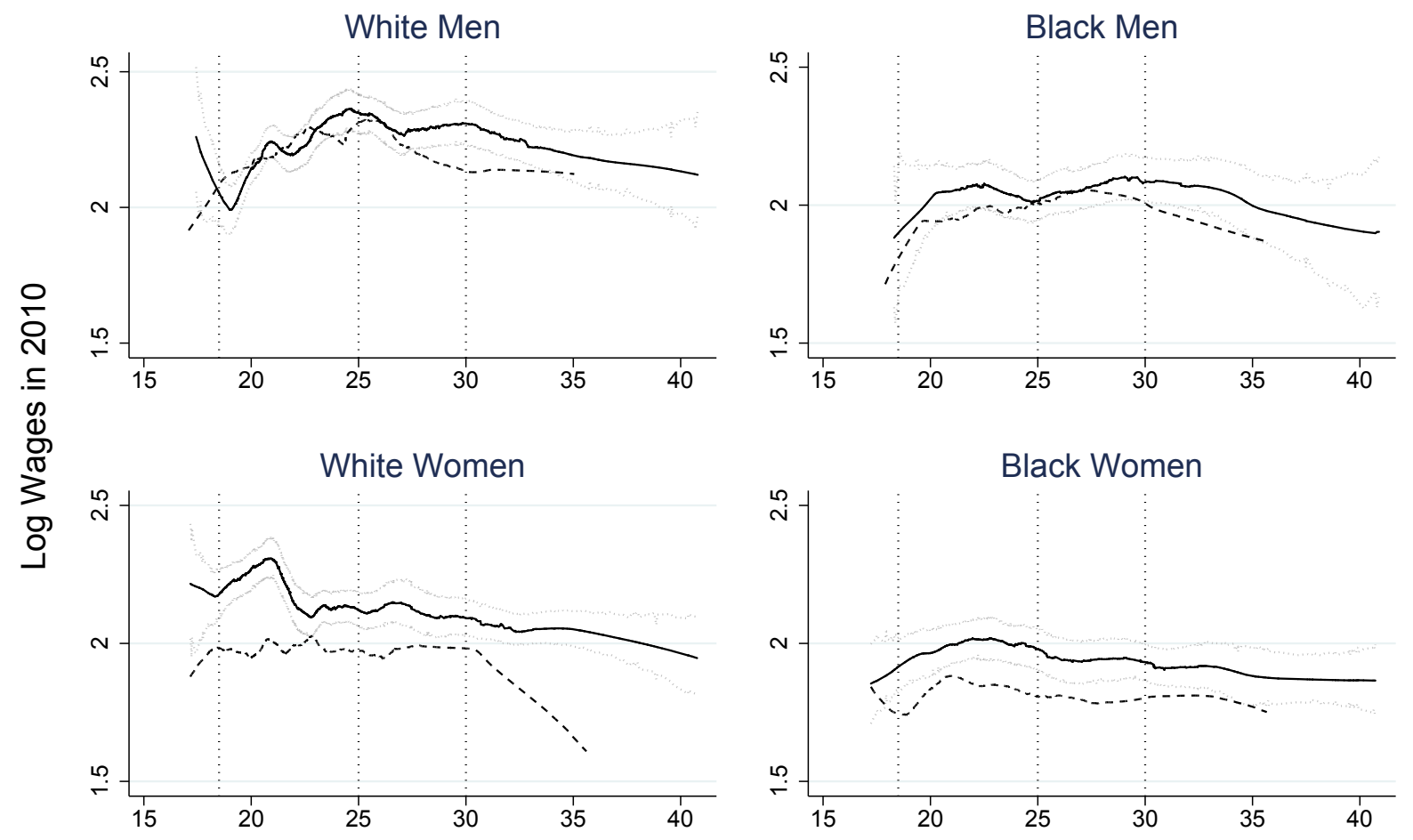

BMl in 2003

Figure 4: Results from semiparametric linear regression of log wages in 2010 on BMI in 2003, NLSY-1997.

Notes: Vertical, dotted lines show standard BMI cutoffs: $<18.5$, “Underweight"; 18.5-24.9, “Normal”; 25-29.9, "Overweight"; $\geq 30$, "Obese." The dashed line without confidence intervals shows values for the NLSY-79 cohort from Figure 1. Models control for education, age, ASVAB, region of residence, work experience, and industry. Wages are adjusted to 1988 dollars.

Women in the 1997 cohort also display a flattening of the association between the likelihood of being married and BMI. For white women, the relationship is still negative. The change point results show that this association is captured by a simple downward-sloping line, albeit with a much shallower slope of -0.006 ( $p$ $=0.05$ ) for the 1997 cohort. For black women, both the semiparametric curve and the change-point model suggest no association between BMI and the probability of being married in the 1997 cohort, compared to a negative linear association in the previous cohort. Taken together, the results show that for all groups, the association between the probability of being married and body mass was weaker in the 1997 cohort than it was in the 1979 cohort. Moreover, for black men and women, we find no statistically significant negative correlation between the probability of marriage and BMI in any part of the BMI distribution in the 1997 cohort.

\section{Cohort Family Income}

The results in Figure 6 show a relatively flat association between BMI and family income for all groups except black men. For black men, the semiparametric curve 

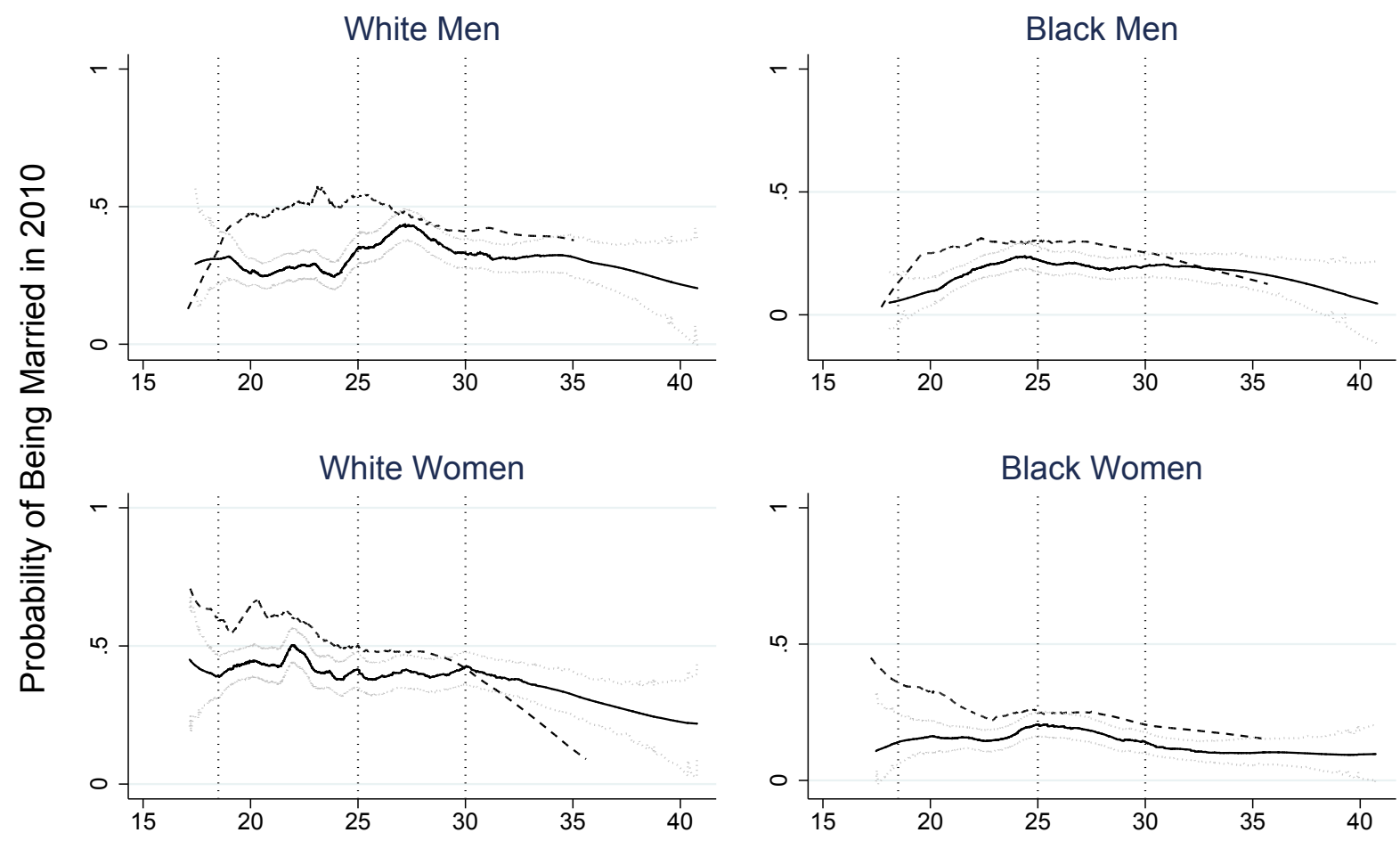

BMl in 2003

Figure 5: Results from semiparametric linear regression of the probability of being married in 2010 by BMI in 2003, NLSY-1997.

Notes: Vertical, dotted lines show standard BMI cutoffs: <18.5, “Underweight"; 18.5-24.9, "Normal"; 25-29.9, "Overweight"; $\geq 30$, "Obese." The dashed line without confidence intervals shows values for the NLSY-79 cohort from Figure 2. Models are linear probability models estimated only for those never married in 2003 and control for education, age, ASVAB, and region of residence.

for the 1997 cohort is flatter than the curve for the 1979 cohort, but it is upward sloping. The change point results shown in column 2 of Table 4, however, capture no significant association between BMI and family income for any group in the 1997 cohort. For all groups except black women, this is a different pattern than observed in the earlier cohort. In the 1979 cohort, white men had an inverted U-shaped pattern, black men had a significant positive association, and white women had a negative association across nearly the entire distribution of BMI. By the 1997 cohort, these patterns were no longer statistically significant. For black women, the association was flat in both cohorts.

\section{Sensitivity Tests}

In order to check the sensitivity of our results to measurement error resulting from self-reported height and weight data, we used a third data set that includes both measured and self-reported height and weight and offers a longitudinal sample 

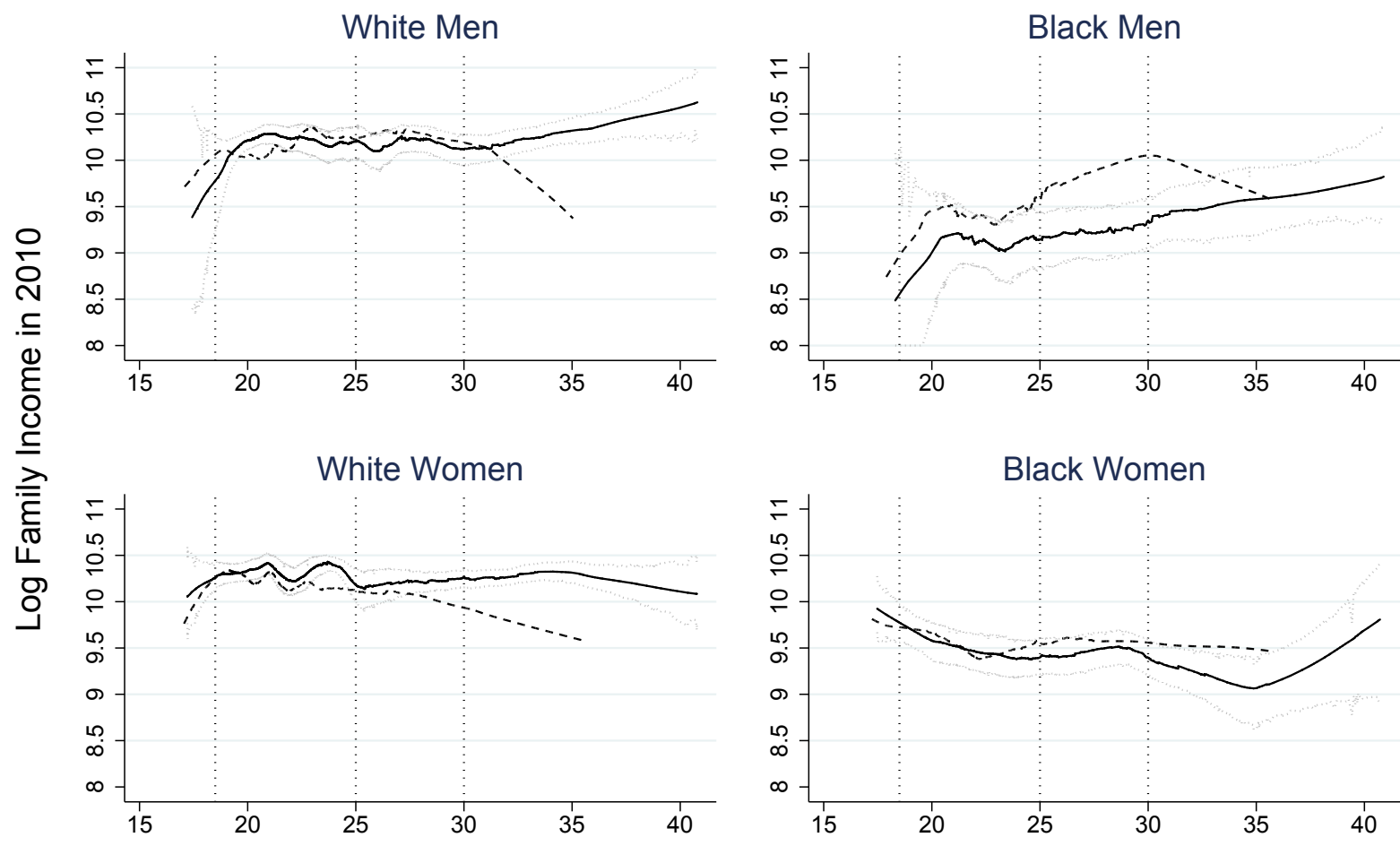

BMl in 2003

Figure 6: Results from semiparametric linear regression of log family income in 2010 by BMI in 2003, NLSY1997.

Notes: Vertical, dotted lines show standard BMI cutoffs: <18.5, “Underweight"; 18.5-24.9, “Normal”; 25-29.9, “Overweight"; $\geq 30$, "Obese." The dashed line without confidence intervals shows values for the NLSY-79 cohort from Figure 3. Models control for education, age, ASVAB, region of residence, and whether respondent lived with a parent in 1988.

of young adults surveyed in nearly the same years as the NLSY-97. The National Longitudinal Study of Adolescent Health (Add Health) is a nationally representative panel data set designed to assess the health behaviors of adolescents. The Add Health sample has a school-based design that is not directly comparable to the NLSY cohorts, which are household samples of distinct birth cohorts. However, the Add Health sample offers a subset of respondents who are the same age as those of the NSLY-97 sample and were interviewed in nearly the same years. Wave III, which was conducted in 2001 and 2002, includes a subset of respondents who were ages 19 to 23 (the NLSY-97 respondents were 19 to 23 in 2003) and provides a baseline measure of BMI. Wave IV, which was fielded seven years later, in 2008 and 2009, allows for a comparable measure of outcomes when the Add Health respondents were 26 to 30 (the NLSY-97 respondents were 26 to 30 in 2010).

The Add Health has two outcome measures that we can compare with our analyses. Although the survey did not measure hourly wages in the same way as the NLSY surveys, it did measure annual labor earnings. We are also able to 
measure the probability of being married for those respondents who were never married at Wave III. Using these data, we constructed the most comparable analyses possible to those reported above in order to see if the patterns differed between self-reported and measured BMI $(N=6,706)$. We show these results in Figure 7 and Figure 8.

For each outcome, we estimated the semiparametric regressions separately for measured BMI and self-reported BMI. We then graphed the resulting predicted values together on the same graph. The dashed lines show the curves for selfreported BMI, the solid lines show the curves for measured BMI, and the confidence intervals shown are those for the measured BMI curves. For both outcomes and all groups, the results are strikingly similar. The self-reported and measured curves differ slightly at the extremes of BMI, but the substantive patterns are identical, and the self-reported curves fit entirely within the confidence intervals of the measured curves. The change point results (not shown) are also quite similar.

We also checked many alternative specifications for our models. Overall, our results are quite robust to different choices about the data or models. We report on two such alternatives. First, we estimated all models without controlling for the cognitive test scores (AFQT/ASVAB) in order to retain the observations with missing values on this variable in the analytical sample. This is important because the ASVAB score is missing for about 17 percent of the NLSY-97 sample. The results for the 1979 cohort are the same whether or not the AFQT scores are included as controls. The results for the 1997 cohort are also substantively the same but with two exceptions. In the marriage models, the relationship between BMI and the likelihood of being married has a marginally significant negative slope at higher values of BMI for black men and black women, whereas these associations are not significant when we controlled for the ASVAB score.

Second, we reestimated the family income models to adjust for differences in household size by dividing family income by the square root of the number of household members. This rescaling of family income changed only one of the eight results in a substantively meaningful way. For white men in the 1979 cohort, the estimated change point moves from 22.8 to 32.8, with a flat slope from a BMI of 17 to 32.8 , rather than the positive slope estimated when family income is not rescaled. The slope from a BMI of 32.8 to 35 is negative.

\section{Discussion and Conclusion}

Examining the association between body mass and socioeconomic outcomes across many different contexts gives a different picture of the social costs of body size than that implied by the categorical or medical approach to studying obesity. First, the patterns for being "too fat" or "thin enough" differ systematically by gender, race, and social outcome. Second, the association between BMI and social outcomes is often not constant within the ranges of the standard cutoffs, which alone calls into question the categorical approach to studying these relationships.

For white men, the association between BMI and outcomes is distinctly nonlinear not only for wages but across all three outcomes. At higher BMIs, heavier white men have worse outcomes, but at low and lower-middle BMIs, outcomes improve as 

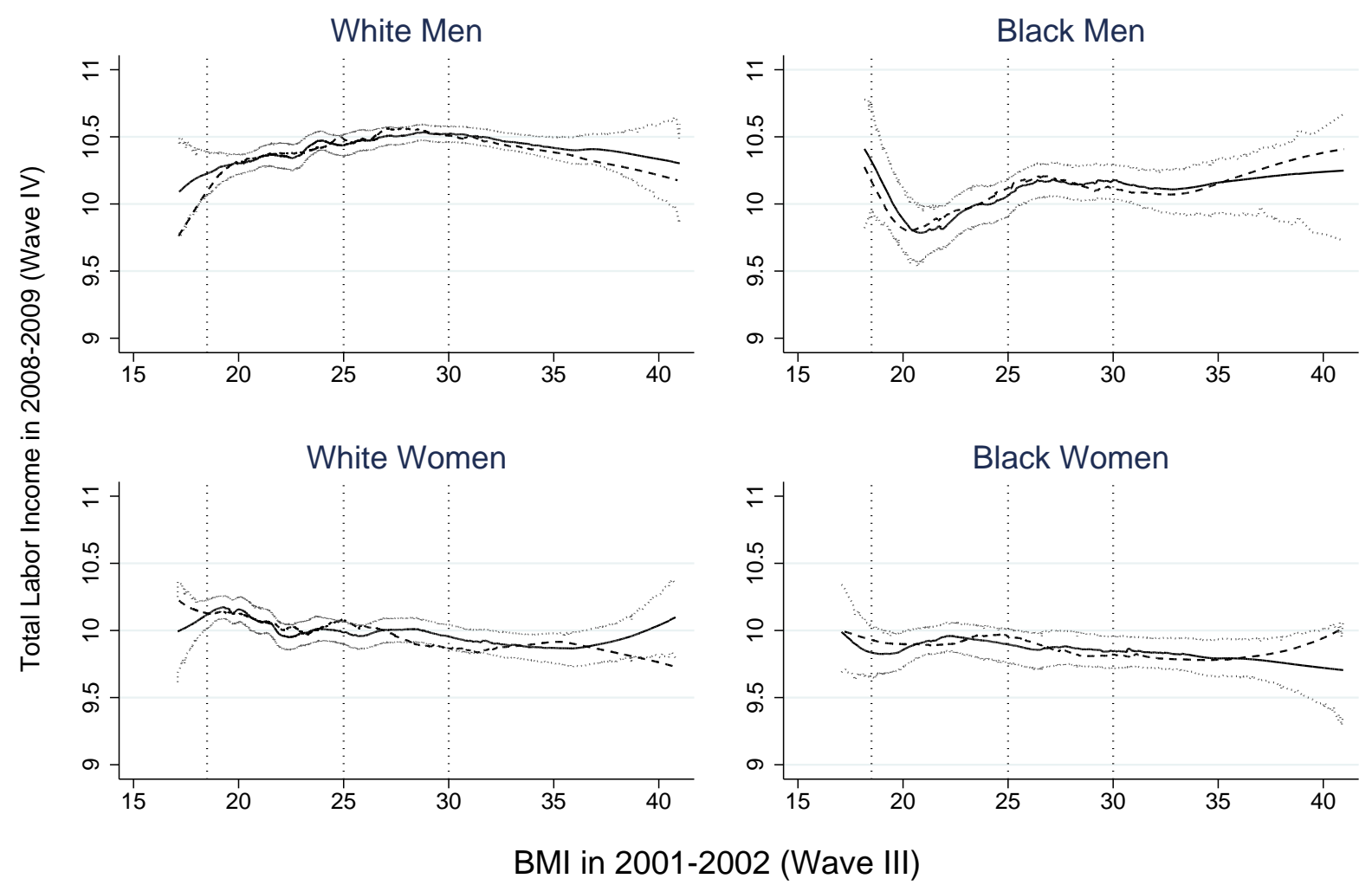

Figure 7: Results from semiparametric linear regression of log annual earnings in 2008-2009 (Wave IV) on BMI in 2001-2002 (Wave III) using measured versus self-reported BMI, Add Health $(N=6,706)$.

Notes: The dashed line shows results from self-reported BMI, the solid line shows results from measured BMI, and confidence intervals shown are for measured BMI. Vertical, dotted lines show standard BMI cutoffs: <18.5, "Underweight"; 18.5-24.9, "Normal"; 25-29.9, "Overweight"; $\geq 30$, “Obese."

BMI increases. This pattern largely persists across cohorts as well. For white women, most of what might be attributed to obesity is instead due to the systematic negative association between BMI and socioeconomic outcomes across the distribution of BMI. The meaningful patterns are about being thin—usually quite thin-rather than being excessively or even moderately fat.

White women's wages in the 1979 cohort are the exception, but this pattern is not present for any other outcome and does not persist in the 1997 cohort. In six of the eight models for white women, the results show a negative linear association between BMI and outcomes starting at very low BMIs. It is possible that body ideals of thinness applied more strictly in the marriage market than the labor market for white women in the earlier cohort. Then, as the prevalence of corpulence increased, the norms for white women in the labor market shifted to a more drastic regime in which thinner is better across the distribution of BMI. A plausible alternative explanation, however, is that this unique pattern for wages is an anomaly of the NLSY-79 sample of white women. 

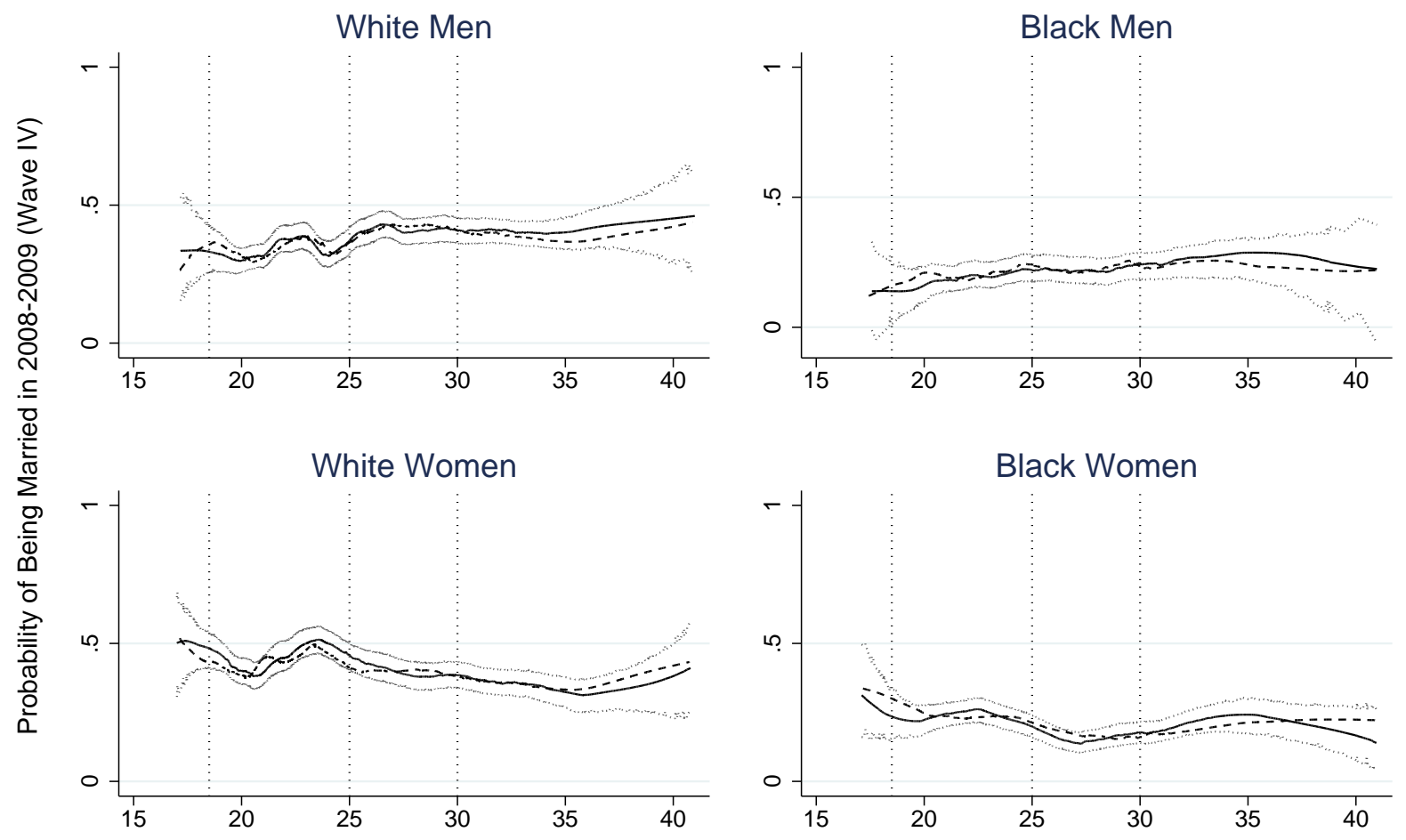

BMI in 2001-2002

Figure 8: Results from semiparametric linear regression of probability of being married at Wave IV (2008-2009) by measured and self-reported BMI at Wave III (2001-2002), Add Health $(N=6,706)$.

Notes: The dashed line shows results from self-reported BMI, the solid line shows results from measured BMI, and confidence intervals shown are for measured BMI. Vertical, dotted lines show standard BMI cutoffs: <18.5, "Underweight"; 18.5-24.9, "Normal"; 25-29.9,

"Overweight"; $\geq 30$, "Obese." Models are linear probability models estimated for those never married at Wave III.

For black men and women, the association between BMI and socioeconomic outcomes dissipated across cohorts. In the 1979 cohort (respondents born between 1957 and 1962), we found little support for widely held beliefs about the greater acceptance of larger women by black Americans. By the 1997 cohort (respondents born between 1980 and 1984), however, there was consistent evidence across multiple social domains that the association between body mass and socioeconomic outcomes becomes systematically weaker for black Americans. Although we do not study body norms directly, our findings suggest that body norms used to differ by gender rather than race but have come to differ distinctly by both gender and race in the more recent cohort.

For all social groups, the association between BMI and the likelihood of being married weakens across cohorts. As average BMIs increase for all groups, it may be that our acceptance of marrying partners who are larger necessarily shifts as well. This weakening association between body mass and marriage in the 1997 cohort, combined with broader demographic shifts in age at marriage and ever marriage, 
translates to a flattening of the association between family income and BMI for all groups. For white Americans, the association between BMI and being married weakens but continues to show a negative correlation that differs by gender. For black Americans, this association weakens as well but is no longer negative in any part of the BMI distribution for either men or women in the 1997 cohort.

White Americans also have a negative association between BMI and wages across both cohorts, albeit at quite different thresholds by gender. Why would the associations differ between the marriage market and labor market? And why do black Americans not show similar patterns across these domains? One possible explanation is that the negative stereotypes regarding people who are fat as lacking self-control or being perceived as lazy (Puhl and Heuer 2009) may apply more narrowly to the domain of work, or the perceived costs associated with these stereotypes may seem more relevant for employment than marriage. These stereotypes may also apply more strongly to white Americans than black Americans. The lack of a systematic negative association between BMI and wages for black Americans by the 1997 cohort suggests that the acceptance of larger bodies for black Americans may be shared not only by other black Americans but also by white Americans. Although marriage markets are quite segregated, the labor market is less so.

The patterns for all women in the 1979 cohort and white women in the 1997 cohort remind us that norms of thinness dominate women's lives at work and at home. But, we are also struck by the evidence that a body ideal operates for white men in multiple domains as well. This ideal is not a systematic reward to thinness, as it is for white women, but instead is a body that is not too thin and not too large. Many of the semiparametric curves for white men peak near the cusp of the "normal" and "overweight" ranges. BMIs in this range may be due to having more muscle mass or some extra fat, producing frames that are neither too thin nor too large. Together, this is consistent with gendered body norms for white Americans in which women are thinner and men are bigger, but neither partner is particularly corpulent.

The cohort patterns show stability for white Americans and fluidity for black Americans. It is important to note, however, that these relationships are embedded in a social fabric that is also changing. Not only is the distribution of BMI shifting across cohorts, but the timing of demographic transitions such as marriage, childbearing, and leaving home also shift between cohorts. In more recent cohorts, individuals marry later, have lower probabilities of ever marrying, are older when they leave home, and transition to the labor market later (Furstenberg 2010). Our results for marriage only generalize to individuals who marry by ages 26 to 31 , which given the broader demographic trends is a more selective sample in the more recent cohort, especially for African Americans. We have used ages that make our study comparable to the established literature so that readers can compare our results with those using the same data but a different approach to how body mass is parameterized. Nonetheless, it is important to recognize that the underlying dynamics are multidimensional.

Although our results are robust across many different specifications, they are not without limitations. First, in order to limit confounding and keep our findings comparable with the existing literature, we limited our analyses to early adulthood 
and thus cannot necessarily generalize our results to other parts of the life course. Broader life course mechanisms such as early family socioeconomic status and experiences in adolescence may also link BMI and socioeconomic outcomes in adulthood (Ferraro, Thorpe, and Wilkinson 2003; Carr, Jaffe, and Friedman 2008). Second, in several models, we found that the change-point model fits better than a simple line- that is, the results are consistent with a distinct change in the correlation across the distribution of BMI-but our estimate of the change point itself is imprecise. In these cases, the semiparametric regression results show patterns that are quite consistent with the change-point models; however, the results of these specific change points should be interpreted with caution.

Taken together, our results show that the biological and social costs of being (or being judged as) "too fat" cannot be conceptualized or measured in the same way. Our findings argue against taking a binary view of bodies as being "too fat" versus not. Many of the patterns are as much about being thin as being fat. Moreover, accepting "too fat" as an objective standard obscures the fact that the most relevant associations between body size and outcomes are shaped by gender, race, and context rather than any given value of BMI. The relationship between body size and socioeconomic outcomes depends on who is being judged, who is doing the judging (we can only infer this indirectly in our study), and in which social domain. Rather than using the medical conceptualization of obesity, it is important to recognize that "too fat" is a subjective, contingent, and fluid judgment in the social world.

\section{Notes}

$1 \mathrm{BMI}$ is calculated as weight in kilograms divided by height in meters squared. A BMI score below 18.5 is called "underweight"; from 18.5 to 24.9 is "normal"; from 25 to 29.9 is "overweight"; and 30 and above is considered "obese."

2 The contemporaneous relationship between BMI and wages may also be bidirectional. BMI may cause one to earn lower wages, but lower wages might cause one to depend on cheaper, higher-calorie foods, which in turn could increase BMI.

3 This variable is "net" family income in NLSY-79, whereas it is the "gross" family income in NLSY-97. The surveys top-coded this variable at \$100,001 in 1988 and \$290,810 in 2010.

4 The ASVAB data are missing for about 17 percent of the NSLY-97 sample. BMI is not associated with having a missing value on the ASVAB variable. Below, we report on sensitivity analyses that confirm our results are robust to this sample selection.

5 This is a test on two degrees of freedom: the change point and two slopes versus a single slope. The simple line with only one slope is nested in the model with one knot and two slopes, which is in turn nested in a model with two knots and three slopes.

\section{References}

Altabe, Madeline. 1998. "Ethnicity and body image: Quantitative and qualitative analysis." The International Journal of Eating Disorders 23:153-159. https ://doi .org/10.1002/ (SICI) 1098-108X (199803) 23:2<153: : AID-EAT5>3 . 0 . C0;2-J

Averett, Susan, and Sanders Korenman. 1996. "The economic reality of the beauty myth." Journal of Human Resources 31:304-330. https://doi .org/10.2307/146065 
Averett, Susan, and Sanders Korenman. 1999. "Black-white differences in social and economic consequences of obesity." International Journal of Obesity, 23:166-173. https : //doi .org/ $10.1038 / \mathrm{sj}$.ijo.0800805

Baum, Charles L., and William F. Ford. 2004. "The wage effects of obesity: A longitudinal study." Health Economics 13:885-899. https://doi.org/10.1002/hec. 881

Bhattacharya, P. 1994. "Some aspects of change-point analysis." In Change-point Problems, E. Carlstein, H. Muller \& D. Siegmund, eds., pp. 28-56, Institute of Mathematical Statistics, Hayward. https://doi .org/10.1214/lnms/1215463112

Bordo, Susan. 1993. Unbearable Weight: Feminism, Western Culture, and the Body. Berkeley: University of California Press.

Burkhauser, Richard V., and John Cawley. 2008. "Beyond BMI: The Value of More Accurate Measures of Fatness and Obesity in Social Science Research." Journal of Health Economics 27: 519-529. https://doi.org/10.1016/j.jhealeco.2007.05.005

Cachelin, Fary M., Grace H. Chung, Elizabeth Pelayo, and Ramona M. Rebeck. 2002. "Does ethnicity influence body-size preference? A comparison of body image and body size." Obesity Research 10:158-166. https ://doi .org/10.1038/oby .2002.25

Carmalt, Julie H., John Cawley, Kara Joyner, and Jeffery Sobal. 2008. “Body weight and matching with a physically attractive romantic partner." Journal of Marriage and Family 70:1287-1296. https://doi.org/10.1111/j.1741-3737.2008.00566.x

Carr, Deborah, Micheal A. Friedman, and Karen Jaffe. 2008. "Perceived interpersonal mistreatment among obese Americans: Do race, class, and gender matter?" Obesity 16:60-68. https://doi.org/10.1038/oby.2008.453

Cawley, John. 2004. "The impact of obesity on wages." Journal of Human Resources 39:451-474. https://doi.org/10.2307/3559022

Centers for Disease Control and Protection. 2000. "Clinical growth charts." Retrieved from: http:/ / www.cdc.gov/growthcharts/clinical_charts.htm\#Set1

Chang, Virginia W, and Diane S. Lauderdale. 2005. "Income disparities in body mass index and obesity in the United States, 1971-2002." Archives of Internal Medicine 165:2122-2128. https://doi.org/10.1001/archinte.165.18.2122

Conley, Dalton, and Rebecca Glauber. 2007. "Gender, body mass and socioeconomic status: New evidence from the PSID." Advances in Health Economics and Health Services Research 17:253-275. https://doi .org/10.1016/S0731-2199(06)17010-7

Ferraro, Kenneth F., Roland J. Thorpe, and Jody A. Wilkinson. 2003. "The life course of severe obesity: Does childhood overweight matter?." The Journals of Gerontology Series B: Psychological Sciences and Social Sciences 58:110-119. https://doi .org/10.1093/geronb/ 58.2.S110

Fletcher, Jason M. 2014. The interplay between gender, race and weight status: Self perceptions and social consequences. Economics \& Human Biology 14:79-91. https: //doi.org/10.1016/j.ehb.2012.03.003

Furstenberg, Frank. 2010. "On a new schedule: Transitions to adulthood and family change." The Future of Children 20:67-87. https : //doi .org/10.1353/foc.0.0038

Glass, Christy M., Steven A. Haas, and Eric N. Reither. 2010. “The skinny on success: Body mass, gender and occupational standing across the life course." Social Forces 88:1777-1806. https://doi.org/10.1353/sof .2010.0012

Glasser, Carol L., Belinda Robnett, and Cynthia Feliciano. 2009. “Internet daters' body type preferences: Race-ethnic and gender differences." Sex Roles 61:14-33. https: //doi .org/ $10.1007 /$ s11199-009-9604-x 
Gordon-Larsen, Penny, Linda S. Adair, Melissa C. Nelson, and Barry M. Popkin. 2004. “Fiveyear obesity incidence in the transition period between adolescence and adulthood: The national longitudinal study of adolescent health." American Journal of Clinical Nutrition 80:569-75.

Gortmaker, Steven L., Aviva Must, James M. Perrin, Arthur M. Sobel, and William H. Dietz. 1993. "Social and economic consequences of overweight in adolescence and young adulthood." New England Journal of Medicine 329:1008-1012. https : //doi . org/10.1056/ NEJM199309303291406

Gregory, Christian A., and Christopher J. Ruhm. 2011. "Where does the wage penalty bite?" in Michael Grossman and Naci Mocan (Eds.) Economic Aspects of Obesity: NBER Conference Report, pp. 315-347, Chicago and London: University of Chicago Press. https : //doi.org/10.7208/chicago/9780226310107.003.0012

Hall, Charles B., Richard B. Lipton, Martin Sliwinski, and Walter F. Stewart. 2000. "A change point model for estimating the onset of cognitive decline in preclinical Alzheimer's disease." Statistics in Medicine 19:1555-1566. https://doi.org/10.1002/ (SICI) 1097-0258(20000615/30) 19:11/12<1555: :AID-SIM445>3.0.C0;2-3

Han, Euna, Edward C. Norton, and Sally C. Stearns. 2009. "Weight and wages: Fat versus lean paychecks." Health Economics 18:535-548. https://doi .org/10.1002/hec.1386

Hebl, Michelle R., and Todd F Heatherton. 1998. "The stigma of obesity: The differences are black and white." Personality and Social Psychology Bulletin 24:417-426. https : //doi .org/ 10.1177/0146167298244008

Hebl, Michelle R., and Julie M. Turchin. 2005. "The stigma of obesity: What about men?" Basic and Applied Social Psychology 27:267-275.ence https://doi .org/10.1207/ s15324834basp2703_8

Kalmijn, Mattias. 1998. "Intermarriage and homogamy: Causes, patterns, trends." Annual Review of Sociology 24:395-421. https : //doi .org/10.1146/annurev . soc . 24.1.395

Loh, Eng Seng. 1993. “The economic effects of physical appearance." Social Science Quarterly 74:420-438.

Lorber, Judith, and Patricia Yancey Martin. 2000. "The Socially Constructed Body" in Peter Kivisto (Ed.) Illuminating Social Life: Classical and Contemporary Theory Revisited, pp. 226-244, Los Angeles: Sage.

Lundborg, Petter, Paul Nystedt, and Dan-Olof Rooth. 2014. “Body size, skills, and income: Evidence from 150,000 teenage siblings." Demography 51:1573-1596 https : //doi .org/ $10.1007 / \mathrm{s} 13524-014-0325-6$

Maranto, Cheryl L., and Ann Fraedrich Stenoien. 2000. “Weight discrimination: A multidisciplinary analysis." Employee Responsibilities and Rights Journal 12:9-24. https: //doi.org/10.1023/A:1007712500496

Ogden, Cynthia L., Susan Z. Yanovski, Margaret D. Carroll, and Katherine M. Flegal. 2007. "The epidemiology of obesity." Gastroenterology 132:2087-2102. https://doi.org/10. $1053 / j$.gastro.2007.03.052

Oreffice, Sonia, and Climent Quintana-Domeque. 2010. "Anthropometry and socioeconomics among couples: Evidence in the United States." Economics E Human Biology 8:373-384. https://doi.org/10.1016/j.ehb.2010.05.001

Pope, Harrison G., Roberto Olivardia, Amanda Gruber, and John Borowiecki. 1999. “Evolving ideals of male body image as seen through action toys." International Journal of Eating Disorders 26:65-72. https : //doi.org/10.1002/(SICI) 1098-108X (199907) 26: 1<65: : AID-EAT8>3 . 0. CO;2-D 
Puhl, Rebecca M., and Kelly Brownell. 2001. "Bias, discrimination, and obesity." Obesity Research 9:788-905. https://doi.org/10.1038/oby.2001.108

Puhl, Rebecca M., and Chelsea Heuer. 2009. "The stigma of obesity: A review and update." Obesity 17:941-964. https://doi.org/10.1038/oby.2008.636

Register, Charles A., and Donald R. Williams. 1990. “Wage effects of obesity among young workers." Social Sciences Quarterly 71:130-141.

Saguy, Abigail. 2014. What's Wrong with Fat? London: Oxford University Press.

Sobal, Jeffery, and Albert J. Stunkard. 1989. "Socioeconomic status and obesity: a review of the literature." Psychological Bulletin 105:260-275. https://doi.org/10.1037/ 0033-2909.105.2.260

Speakman, John R., Kurosh Djafarian, Joanne Stewart, and Diane M. Jackson. 2007. “Assortative mating for obesity." The American Journal of Clinical Nutrition 86:316-323.

Synnott, Anthony. 1992. "Tomb, temple, machine and self: The social construction of the body." British Journal of Sociology, 43:79-110. https://doi .org/10.2307/591202

Wiseman, Claire V., James J. Gray, James E. Mosimann, and Anthony H. Ahrens. 1992. "Cultural expectations of thinness in women: An update." International Journal of Eating Disorders 11: 85-89. https://doi.org/10.1002/1098-108X(199201) 11:1<85: : AID-EAT2260110112>3.0.CO;2-T

Yatchew, Adonis. 1998. Nonparametric regression techniques in economics. Journal of Economic Literature 36:669-721.

Zacks, Shelemyahu. 1982. "Classical and Bayesian approaches to the change-point problem: Fixed sample and sequential procedures." Stat. Anal. Donnees 7:48-81.

Acknowledgements: We thank Maurice Gesthuizen, Richard Breen, and Jason Fletcher for their comments and suggestions and Sam Stabler, Luke Wagner, Kate Bradley, and Isadora Milanez for providing superb research assistance.

This research uses data from the National Longitudinal Survey of Youth 1979 and 1997, and also data from Add Health, a program project directed by Kathleen Mullan Harris and designed by J. Richard Udry, Peter S. Bearman, and Kathleen Mullan Harris at the University of North Carolina at Chapel Hill, and funded by grant P01HD31921 from the Eunice Kennedy Shriver National Institute of Child Health and Human Development, with cooperative funding from 23 other federal agencies and foundations. Special acknowledgment is due Ronald R. Rindfuss and Barbara Entwisle for assistance in the original design. Information on how to obtain the Add Health data files is available on the Add Health website (http:/ / www.cpc.unc.edu/addhealth). No direct support was received from grant P01-HD31921 for this analysis.

Vida Maralani: Department of Sociology, Cornell University.

E-mail: vida.maralani@cornell.edu.

Douglas McKee: Department of Economics, Cornell University.

E-mail: douglas.mckee@cornell.edu. 